\title{
Clinical and public health significance of treatments to aid smoking cessation
}

\author{
R. West and J. Stapleton
}

ABSTRACT: There is good epidemiological evidence to show that for every continued year of smoking over the age of $\mathbf{4 0}$ yrs, the average smoker loses $\mathbf{3}$ months of life expectancy.

Treatments to aid smoking cessation have the potential to save tens of thousands of lives annually if they: 1) lead users of those treatments to stop significantly earlier than they would otherwise have done; 2) do not undermine quitting in nonusers; and 3) are used by a significant proportion of smokers. There is strong evidence from high-quality randomised controlled trials to show that currently available treatments improve the chances of a cessation attempt succeeding permanently by between 2.5 and $10 \%$ points. For each success this brings forward quitting by an average of 25-30 yrs. Failure of a cessation attempt at 40 yrs of age costs an estimated 6-7 yrs of life expectancy.

There is no evidence that introducing and publicising treatments undermines quitting in nonusers. The major factor limiting the public health benefit of treatments to aid cessation is the numbers of smokers that use them. At present, the most effective treatment combination of behavioural support plus medication is used by a very small minority of smokers.

It is estimated that for every 100,000 smokers who use proven treatments to aid cessation, between 7,500 and 30,000 life-years will be saved in the future depending on the treatment. In England (UK), the use of smoking cessation treatment in 2008 is expected to save 270,000 lifeyears. A major priority for tobacco control should be finding ways of encouraging more smokers to use the most effective treatments.

KEYWORDS: Clinical health, public health, smoking cessation

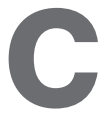

igarette smoking remains one of the most important causes of premature death and morbidity worldwide [1]. The range of fatal and nonfatal diseases caused or exacerbated by smoking is extensive (table 1) [2-9]. The present article discusses why treatments to aid smoking cessation are a crucial element of tobacco control policy and the importance of efforts to encourage as many smokers as possible to use them. There have already been numerous articles published on this issue but the present article makes the case by using a "route to quit" model to estimate the population benefits in terms of ex-smokers created and life-yrs gained per 100,000 smokers who use treatment rather than trying to stop unaided.

\section{THE IMPORTANCE OF EARLY CESSATION}

The benefits of smoking cessation have been well documented [10]. From a large cohort study of British doctors, it is possible to estimate that over the age of $40 \mathrm{yrs}$ bringing forward the date of cessation by $1 \mathrm{yr}$ extends life expectancy by 3 months [11]. According to these data, lifelong smokers lose an average of 10 yrs of life. Smokers who stop smoking at 40 yrs of age recover nine out of these 10 yrs. Stopping smoking at almost any age has a benefit, so that, for example, stopping at the age of 60 yrs recovers 4 yrs.

Figure 1 plots the gain in life expectancy from stopping smoking at different ages, based on the British Doctor study [11]. Presenting the data in this way makes it clear that the greatest benefit in terms of cessation occurs at around 30-40 yrs of age. Up until that age, smokers have the chance to recover most of their life expectancy by stopping smoking. After that age the number of life-yrs gained reduces year by year.

The current authors do not have comparable data from other population subgroups and it is possible that the benefits of stopping smoking at different ages would be greater or smaller depending on the population subgroup concerned. For example, low-income smokers or smokers in countries with a relatively short life expectancy might benefit less from stopping because of the presence of other risk factors.
AFFILIATIONS

Dept of Epidemiology and Public Health, Behaviour Research Centre, London, UK.

CORRESPONDENCE

R. West

Cancer Research UK Health Behaviour Research Centre University College London 2-16 Torrington Place London WC1E 6BT UK E-mail: robert.west@ucl.ac.uk

\section{STATEMENT OF INTEREST}

$R$. West has undertaken research and consultancy for, and received travel funds and hospitality from, companies that develop and manufacture treatments for smoking cessation including Pfizer, GlaxoSmithKline and Johnson and Johnson. He also has a share of a patent in a novel nicotine delivery device. J. Stapleton has occasionally advised organisations with an interest in smoking cessation, including the manufacturers of smoking cessation aids, on clinical trial design and statistics, for which he has received renumerations. 


\begin{tabular}{l} 
TABLE 1 Fatal and serious nonfatal disorders for which \\
tobacco use is a known or probable cause or \\
exacerbating factor \\
Smoking \\
Cancer of the lung \\
Cancer of the larynx \\
Cancer of the oesophagus \\
Cancer of the oropharynx \\
Cancer of the kidney \\
Cancer of the cervix \\
Cancer of the pancreas \\
Cancer of the stomach \\
Cancer of the bladder \\
Leukaemia \\
COPD \\
Pneumonia \\
Asthma attacks \\
Coronary heart disease \\
Aortic aneurism \\
Cerebrovascular disease \\
Peripheral vascular disease \\
Vascular dementia \\
Macular degeneration \\
Cataract \\
Hearing loss \\
Infertility \\
Spontaneous abortion \\
Stillbirth \\
Low birth weight \\
SIDS \\
Low back pain \\
Osteoporosis \\
Tuberculosis \\
Type II diabetes \\
Septic ulcer disease \\
\hline
\end{tabular}

COPD: chronic obstructive pulmonary disease; SIDS: Sudden Infant Death Syndrome. Sources: All [3], except vascular dementia [4], macular degeneration [5], low back pain [6], tuberculosis [7], diabetes [8] and smokeless tobacco [9]. Reproduced from [2] with permission from the publisher.

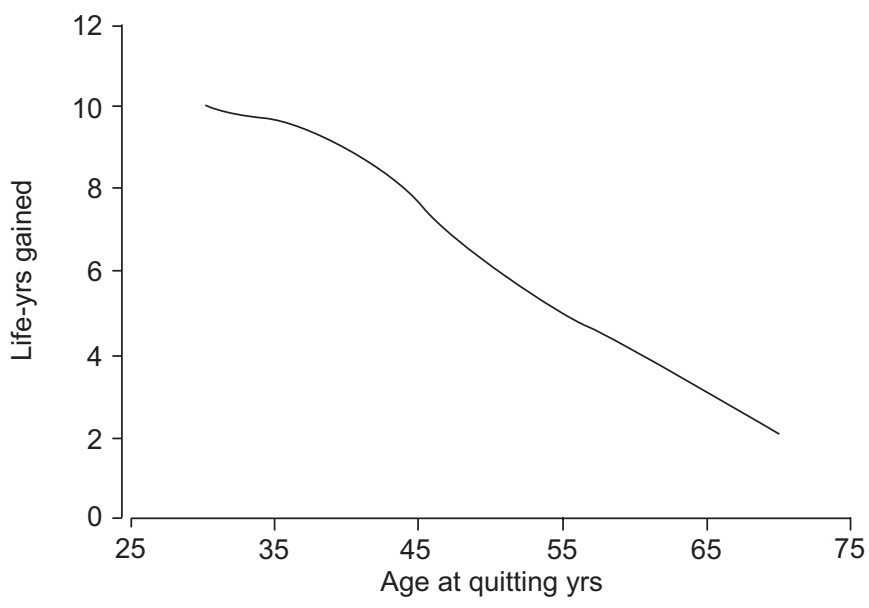

FIGURE 1. The number of life-years gained from smoking cessation at different ages. Data taken from [11].

Alternatively, they might benefit more because of synergistic relationships between smoking and other risk factors or because they take in higher levels of toxin intake from the cigarettes. As new data become available, one could adjust the curve to take account of this but in the meantime these are the best data available.

There is also good evidence from studies of smoking cessation treatment programmes that cessation after onset of smokingrelated disease improves health and life expectancy. The USA Lung Health study showed that smokers with mild-to-moderate chronic obstructive pulmonary disease allocated to an intervention involving extended treatment with nicotine gum and behavioural support had lower mortality rates at 15 -yr followup than those receiving usual care, which involved brief advice to stop smoking [12]. Another randomised trial found that in smokers who had had a myocardial infarction, those who had received intensive cessation treatment had lower mortality at follow-up than those receiving brief advice [13].

Overall, the evidence for the benefit of smoking cessation is very strong. Even smokers who have begun to experience smoking-related disease can expect to gain health and life expectancy and there is no doubt that the earlier a smoker stops the greater the gain in life expectancy.

TABLE 2 Definition of cigarette addiction and nicotine dependence

\begin{tabular}{lcc} 
Description & Measurement \\
\hline Cigarette addiction & $\begin{array}{c}\text { Powerful motivation }{ }^{\#} \text { to smoke cigarettes arising } \\
\text { primarily from abnormalities in physiological functioning } \\
\text { of CNS pathways underlying motivation } \\
\text { Nicotine dependence }\end{array}$ & $\begin{array}{c}\text { Ratings of frequency and strength of urge, want or } \\
\text { need to smoke; behavioural evidence of strong } \\
\text { motivation to smoke } \\
\text { cigarettes or other nicotine-delivery systems }\end{array}$ \\
\hline
\end{tabular}

CNS: central nervous system. " : motivation is used here in the broad sense of all those mental processes that direct and energise behaviour, not merely "reasons". 

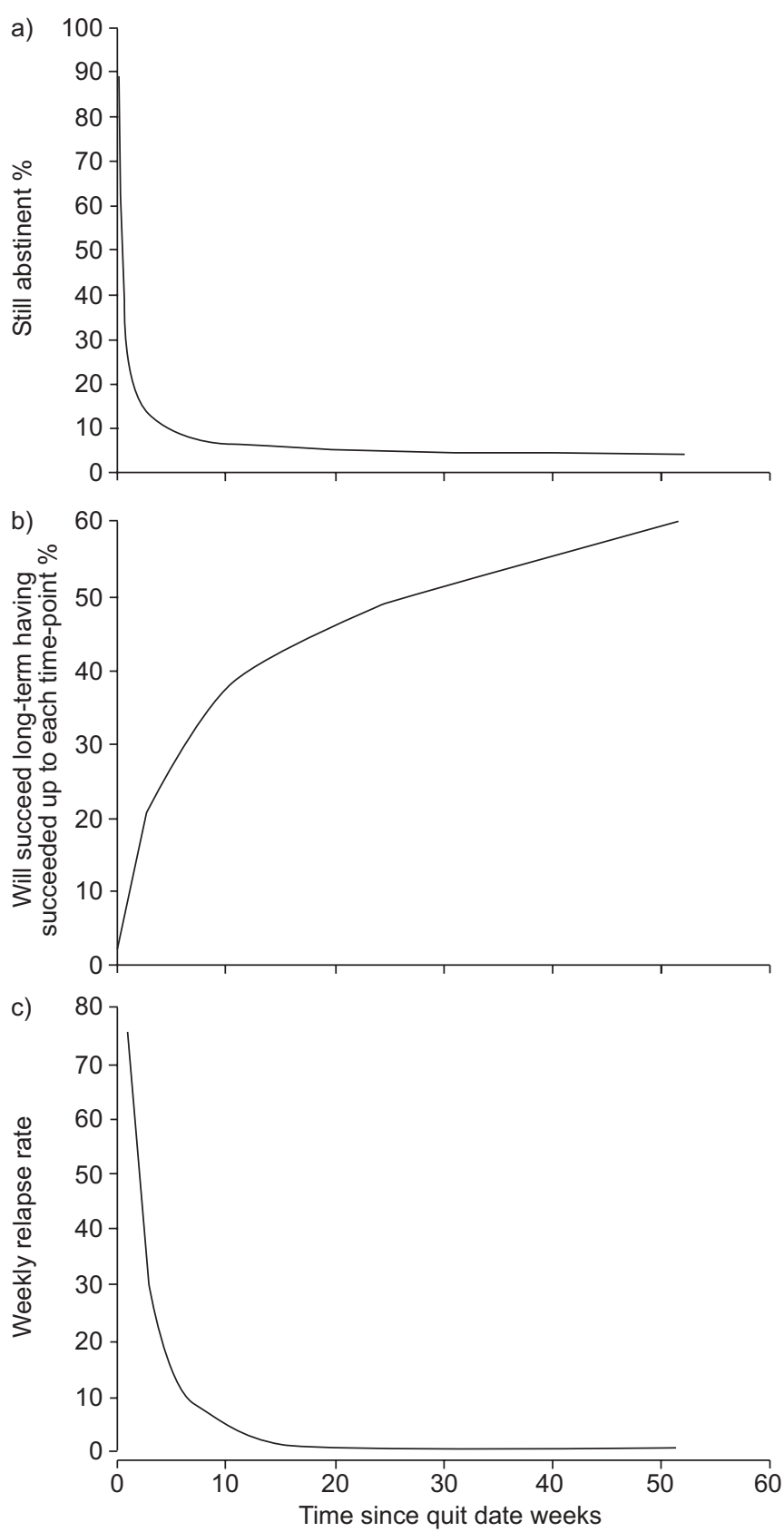

FIGURE 2. The typical relapse rates with unaided quitting in three different ways. a) The classic survival curve, b) the prognosis curve, and c) the relapse-risk curve.

\section{TREATMENT TO AID SMOKING CESSATION}

\section{The need for treatment}

Treatment is the term given to medical interventions to relieve illness or injury. Illness can be defined as: impairment of normal physiological function affecting part or all of an organism. Therefore, cigarette smoking is not an illness (it is a behaviour pattern), and hence one cannot "treat" cigarette smoking. However, it has become apparent that for many smokers there is an illness underlying their continued smoking: cigarette addiction. Like other illnesses it varies in severity and often has fatal consequences. In this case the fatalities arise because of the diseases caused by continued smoking. In the case of cigarette addiction, the abnormality lies primarily in the physiology of the motivational system which leads to powerful urges to smoke that undermine and overwhelm resolve not to smoke.

The terms "nicotine dependence", "nicotine addiction", "cigarette addiction", "tobacco dependence" and "tobacco addiction" are often used interchangeably [14]. This is potentially confusing; the key concepts appear to be cigarette addiction and nicotine dependence, with the former referring essentially to a motivation, and the latter referring to a physiological abnormality (table 2). Whichever terminology one uses, the key observations are as follows. 1) Many smokers experience powerful motivation to smoke, and adverse mood and physical symptoms if they attempt abstinence [15, 16]. 2) There are marked structural and functional abnormalities in the central nervous system (CNS), including upregulation of nicotinic acetylcholine receptors [17], sensitisation of parts of the nucleus accumbens to nicotine [18] and reduced tonic firing of the CNS pathway concerned [18]. 3) The motivation to smoke deters attempts to stop and undermines and frustrates those attempts when they occur leading to very high rates of relapse [19].

Treatment for cigarette addiction involves interventions designed to prevent smoking for a period of several months to allow the CNS to recover and the physiological causes of the powerful motivations to smoke to diminish. It can involve: 1) pharmacological treatments to reduce the motivation to smoke; and 2) behavioural support to reduce motivation to smoke, increase motivation not to smoke, maximise selfregulatory capacity and ensure appropriate use of pharmacological treatments.

Figure 2 shows the typical relapse rates with unaided quitting in three different ways. The classic survival curve (fig. 2a) indicates that only $\sim 25 \%$ of serious quit attempts survive the first week and $<5 \%$ survive 6 months. The prognosis for permanent cessation (fig. 2b) improves the longer cessation continues and improves five-fold in the first 4 weeks. The weekly risk of relapse with time since the quit point (fig. 2c) shows very clearly that this risk is very high in the first 4 weeks and becomes very low after $\sim 12$ weeks. This suggests that the first 12 weeks represents the main period over which most of the recovery occurs and should, therefore, be the period in which treatment should be targeted.

\section{Treatment effectiveness}

Treatments to aid smoking cessation vary in effectiveness from a 5 percentage point increase in 6 month abstinence per treatment episode for behavioural support to 15 percentage points for varenicline (Pfizer, New York, NY, USA) [20-25]. In all cases, the benefits of treatment have been established through multiple high-quality randomised controlled trials. Table 3 shows the main forms of treatment and broad estimates of their effectiveness obtained from randomised controlled trials.

Long-term follow-up of smokers attempting to stop shows that $\sim 20 \%$ relapse between 6 months and $1 \mathrm{yr}$ and 30\% relapse after this time $[26,27]$. Thus, the effect on permanent cessation of a treatment episode can be estimated as $50 \%$ of that of the 
TABLE 3 Effectiveness of treatments to aid smoking cessation

\begin{tabular}{|c|c|c|c|}
\hline Treatment & Comparison & $\begin{array}{l}\text { Increase in those abstinent } \\
\text { for } 6 \text { months }{ }^{\#}\end{array}$ & $\begin{array}{l}\text { Increase in permanent abstinence } \\
\text { as a result of treatment }\end{array}$ \\
\hline \multicolumn{4}{|l|}{$\begin{array}{l}\text { Nicotine replacement therapy all forms 8- } \\
12 \text { weeks }\end{array}$} \\
\hline Without behavioural support & Placebo & 5 & 2.5 \\
\hline With behavioural support & Placebo with behavioural support & 10 & 5 \\
\hline Nortriptyline $1.5 \mathrm{mg}$ b.i.d. 8 weeks & Placebo with behavioural support & 10 & 5 \\
\hline Varenicline $1.5 \mathrm{mg}$ b.i.d. 12 weeks & Placebo with behavioural support & 15 & 7.5 \\
\hline \multicolumn{4}{|l|}{ Behavioural support 4-8 weeks } \\
\hline Face-to-face from a specialist & Brief advice or written materials & 5 & 2.5 \\
\hline Telephone-based & Brief advice or written materials & 5 & 2.5 \\
\hline $\begin{array}{l}\text { Combination of behavioural support and } \\
\text { medication }\end{array}$ & Quitting without help & $10-20$ & $5-10$ \\
\hline
\end{tabular}

Data are presented as $\% .{ }^{*}$ : percentage of all smokers treated; thus if the placebo rate is $5 \%$ and the active treatment rate is $10 \%$ the increase is $5 \%$. Figures are based on percentage differences in relevant tables from the Cochrane reviews [20-25] rounded to the nearest $5 \%$. ${ }^{\natural}: 50 \%$ of the effect size at 6 months.

6-month effect. Table 3 shows that treatment to aid cessation can vary in effectiveness but that a combination of medication and behavioural support can yield an increase of 10 percentage points (from 5 to $15 \%$ ) in permanent quit rates of treated smokers.

When considering the effect of treatments to aid smoking cessation it is necessary to bear in mind that after a given

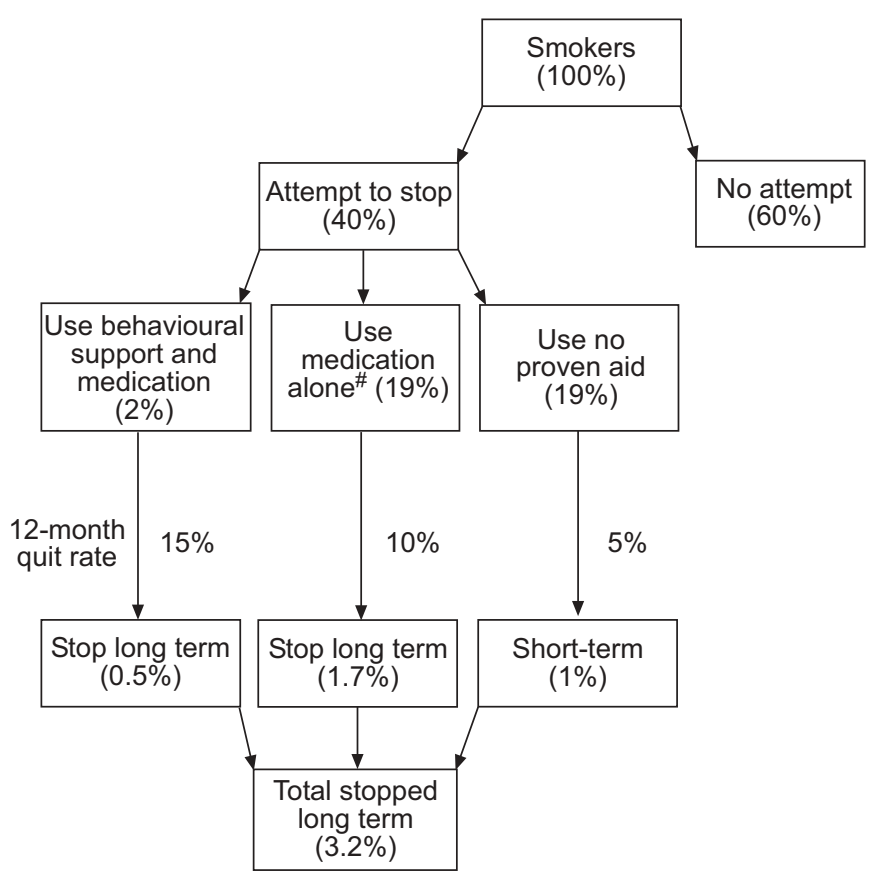

FIGURE 3. The "route to quit" model, which indicates the contribution of different ways of quitting to overall rates of smoking cessation. * : in most cases nicotine replacement therapy was bought over the counter. treatment episode, smokers are likely to continue to try to stop if they fail on that occasion. Population-level studies give rise to estimates of $2-3 \%$ of smokers quitting permanently each year [28]. From this it can be estimated that failure of a given attempt to stop results in an average of 25-30 yrs of continued smoking or death, whichever comes first. The average loss of life expectancy resulting from a cessation attempt failing at $40 \mathrm{yrs}$ of age therefore is 6-7 yrs ( 3 months loss of life expectancy for every year that quitting is delayed).

\section{WHAT EFFECT DOES PROMOTING TREATMENT HAVE ON THE POPULATION OF SMOKERS?}

The argument may be raised that promoting treatment to aid cessation sends out a signal to smokers that it is difficult to stop without help and thus deters quitting in those smokers who are not willing or able to use treatment [29]. There is no evidence to support this view and there is some evidence that goes against it.

If promoting treatment undermined attempts to stop smoking, countries that promote treatment heavily would be expected to have lower rates of attempts to stop but this is not the case. For example, the UK government heavily promotes treatment as part of its tobacco-control strategy [30] and yet $40-50 \%$ of all smokers report attempting to quit each year [31]. When bupropion (GlaxoSmithKline, Research Triangle Park, NC, USA) was launched in the UK, amid considerable publicity, the rate at which smokers tried to stop remained unchanged but many more used medication to aid their quit attempts [32].

\section{MODELLING THE POPULATION BENEFIT OF TREATMENT TO AID SMOKING CESSATION}

If treatment for smoking cessation does not deter quitting in nonusers, its population benefit depends on its effectiveness and extent of its usage. The preceding section estimated the effect of each treatment episode. It is possible from this to estimate the number of life-yrs gained for every 100,000 
smokers using treatment versus those trying to quit unaided in a given year.

Using the data shown previously, it can be estimate that for every 100,000 smokers using only medication to aid cessation an additional 2,500 permanent successes are obtained. If it is assumed that the age distribution at the time of treatment is such that the average success gains half of the potential life-yrs saved from quitting at $40 \mathrm{yrs}$ of age (half of 6 yrs $=3 \mathrm{yrs}$ ) this amounts to 7,500 life-yrs. The number of life-yrs gained from using behavioural support and medication would be at least double this at 15,000 life-yrs and could be as much as 30,000 life-yrs. If one applies standard discounting rules for health benefits ( $2 \%$ per year) to take into account the fact that these life-yrs are typically saved several decades in the future, one arrives at figures half of those presented. Thus, for every 100,000 smokers using medication only to help them stop smoking it can be estimated that 3,750 discounted life-yrs are gained and for every 100,000 smokers using behavioural support and medication an estimated 7,500-15,000 discounted life-yrs are gained.

Figure 3 shows a route to quit model indicating the contribution of different ways of quitting to overall cessation rates. This version uses data from England (UK) [33] where in 2008: 40\% of smokers reported having made a cessation attempt; $2 \%$ reported attending the National Health Service Stop Smoking Services, which provide behavioural support plus medication; $19 \%$ reported using medication without behavioural support; and $19 \%$ reported trying to quit without using any effective treatment. Applying the figures for success rates achieved by different methods of quitting to these figures it can be estimated that, out of $3.2 \%$ of smokers quitting for at least 12 months in 2008, 0.5\% achieved this through behavioural support and medication, $1.7 \%$ through use of medication alone and $1.0 \%$ without effective treatment. It can be estimated that without the use of treatment the overall quit rate would be less than two-thirds of this figure at $2 \%$ (40\% trying to quit with a success rate of $5 \%$ ).

The data used in this example of the route to quit model involve a number of assumptions. It is assumed that smokers can remember cessation attempts dating back over the past 12 months. This is unlikely to be the case, thus the percentage of smokers actually making cessation attempts may well be higher than can be determined from retrospective surveys. It also assumes that smokers who use treatments are similar to those not using treatments when in fact they are likely to be more nicotine dependent. Improved methodologies will help to refine the model but in its current form it provides a basis for making broad estimates of the contribution of different routes to quitting to overall cessation rates.

Applying the route to quit model to the nine million smokers in England (180,000 use behavioural support and medication and 1.71 million use medication alone) and the estimates of life-yrs gained from use of treatment, it can be estimated that treatment use in 2008 will lead to a saving of 135,000 discounted life-yrs according to the most conservative figures. At the time in the future when they are actually gained, they will mean 270,000 extra years of life among those who succeeded with treatment many years earlier.

\section{CONCLUSIONS}

The present article estimates that every 100,000 treatment episodes can be expected to result in 3,750-15,000 discounted life-yrs saved. In England, where use of nicotine replacement therapy bought over the counter is common and there is a national Stop Smoking Service providing behavioural support and medication, it is conservatively estimated that use of treatment to aid cessation in 2008 will ultimately gain 270,000 life-yrs.

\section{REFERENCES}

1 World Health Organisation. WHO Report on the Global Tobacco Epidemic, 2008. The MPOWER package. Geneva, World Health Organisation, 2008.

2 West R. Tobacco control: present and future. Br Med Bull 2006; 77-78: 123-136.

3 U.S. Department of Health and Human Services. The Health Consequences of Smoking: A Report of the Surgeon General. Atlanta, Department of Health and Human Services, Centers for Disease Control and Prevention, National Center for Chronic Disease Prevention and Health Promotion, Office on Smoking and Health, 2004.

4 Roman GC. Vascular dementia prevention: a risk factor analysis. Cerebrovasc Dis 2005; 20: Suppl. 2, 91-100.

5 Seddon JM, George S, Rosner B. Cigarette smoking, fish consumption, omega-3 fatty acid intake, and associations with age-related macular degeneration: the US Twin Study of Age-Related Macular Degeneration. Arch Ophthalmol 2006; 124: 995-1001.

6 Power C, Frank J, Hertzman C, Schierhout G, Li L. Predictors of low back pain onset in a prospective British study. Am J Public Health 2001; 91: 1671-1678.

7 Watkins RE, Plant AJ. Does smoking explain sex differences in the global tuberculosis epidemic? Epidemiol Infect 2006; 134: 333-339.

8 Meisinger C, Doring A, Thorand B, Lowel H. Association of cigarette smoking and tar and nicotine intake with development of type 2 diabetes mellitus in men and women from the general population: the MONICA/KORA Augsburg Cohort Study. Diabetologia 2006; 49: 1770-1776.

9 Critchley JA, Unal B. Health effects associated with smokeless tobacco: a systematic review. Thorax 2003; 58: 435-443.

10 U.S. Department of Health and Human Services. The Health Benefits of Smoking Cessation: A Report of the Surgeon General. United States Public Health Service, Office on Smoking and Health, 1990.

11 Doll R, Peto R, Boreham J, Sutherland I. Mortality in relation to smoking: 50 years' observations on male British doctors. BMJ 2004; 328: 1519.

12 Anthonisen NR, Skeans MA, Wise RA, Manfreda J, Kanner RE, Connett JE. The effects of a smoking cessation intervention on 14.5-year mortality: a randomized clinical trial. Ann Intern Med. 2005; 142: 233-239.

13 Mohiuddin SM, Mooss AN, Hunter CB, Grollmes TL, Cloutier DA, Hilleman DE. Intensive smoking cessation intervention reduces mortality in high-risk smokers with cardiovascular disease. Chest 2007; 131: 446-452.

14 U.S. Department of Health and Human Services. The Health Consequences of Smoking: Nicotine Addiction: A 
Report of the Surgeon General. United States Public Health Service, Office on Smoking and Health, 1988.

15 Hughes JR. Effects of abstinence from tobacco: etiology, animal models, epidemiology, and significance: a subjective review. Nicotine Tob Res 2007; 9: 329-339.

16 Hughes JR. Effects of abstinence from tobacco: valid symptoms and time course. Nicotine Tob Res 2007; 9: 315-327.

17 Mukhin AG, Kimes AS, Chefer SI, et al. Greater nicotinic acetylcholine receptor density in smokers than in nonsmokers: a PET study with 2-18F-FA-85380. J Nucl Med 2008; 49: 1628-1635.

18 Balfour DJ. The neurobiology of tobacco dependence: a preclinical perspective on the role of the dopamine projections to the nucleus accumbens. Nicotine Tob Res 2004; 6: 899-912.

19 Hughes JR, Keely J, Naud S. Shape of the relapse curve and long-term abstinence among untreated smokers. Addiction 2004; 99: 29-38.

20 Stead LF, Perera R, Bullen C, Mant D, Lancaster T. Nicotine replacement therapy for smoking cessation. Cochrane Database Syst Rev 2008; 3: CD000146.

21 Hughes JR, Stead LF, Lancaster T. Antidepressants for smoking cessation. Cochrane Database Syst Rev 2007; 1: CD000031.

22 Cahill K, Stead LF, Lancaster T. Nicotine receptor partial agonists for smoking cessation. Cochrane Database Syst Rev 2007; 1: CD006103.

23 Stead LF, Perera R, Lancaster T. Telephone counselling for smoking cessation. Cochrane Database Syst Rev 2006; 3: CD002850.
24 Stead LF, Lancaster T. Group behaviour therapy programmes for smoking cessation. Cochrane Database Syst Rev 2005; 2: CD001007.

25 Lancaster T, Stead LF. Individual behavioural counselling for smoking cessation. Cochrane Database Syst Rev 2005; 2 CD001292.

26 Stapleton JA. Smoking prevalence, cessation and relapse. Stat Methods Med Res 1998; 7: 187-203.

27 Etter JF, Stapleton JA. Nicotine replacement therapy for long term smoking cessation: a meta analysis. Tob Control 2006; 15: 280-285.

28 Stapleton JA. Smoking cessation rates in Britain. In: Nicotine Addiction in Britain. A report of the Tobacco Advisory Group of the Royal College of Physicians. London, Royal College of Physicians, 2000; pp. 118-126.

29 Chapman S. Stop-smoking clinics: a case for their abandonment. Lancet 1985; 1: 918-920.

30 Department of Health. The NHS Cancer Plan; a plan for investment, a plan for reform. London, Department of Health, 2000.

31 West R, Sohal T. "Catastrophic" pathways to smoking cessation: findings from national survey. BMJ 2006; 332: 458-460.

32 West R, DiMarino ME, Gitchell J, McNeill A. Impact of UK policy initiatives on use of medicines to aid smoking cessation. Tob Control 2005; 14: 166-171.

33 Smoking in England. www.smokinginengland.info Date last accessed: December 3, 2008. Date last updated: December 1, 2008. 